\title{
Desafios vivenciados por estudantes bolsistas do Programa Universidade para Todos
}

\section{Challenges experienced by Scholarship Students from Programa Universidade para Todos}

\author{
César Leonardo Karnal', Janine Kieling Monteiro ${ }^{2}$, Grace Oliveira dos Santos ${ }^{3}$, \\ Anelise Schaurich dos Santos ${ }^{4}$
}

'Autor para correspondência. Universidade do Vale do Rio dos Sinos. São Leopoldo, Rio Grande do Sul, Brasil. ORCID: 0000-0003-0754-2665. ckarnal@unisinos.br

${ }^{2}$ Universidade do Vale do Rio dos Sinos. São Leopoldo, Rio Grande do Sul, Brasil. ORCID: 0000-0003-2577-1322. janinekm@unisinos.br ${ }^{3}$ Universidade do Vale do Rio dos Sinos. São Leopoldo, Rio Grande do Sul, Brasil. ORCID: 0000-0002-1507-4585. psicologagracesantos@yahoo.com.br ${ }^{4}$ Universidade do Vale do Rio dos Sinos; SOBRESP - Faculdade de Ciências da Saúde. São Leopoldo, Rio Grande do Sul, Brasil. ORCID: 0000-0002-7530-5568. anelise_ssantos@hotmail.com

RESUMO I Esta pesquisa teve como objetivo conhecer as dificuldades para cursar uma graduação em estudantes bolsistas do Programa Universidade para Todos (PROU$\mathrm{NI})$, com bolsa integral, de uma universidade privada do Rio Grande do Sul/Brasil. A ideia para realização desta pesquisa surgiu a partir da constatação que a aprovação no Exame Nacional do Ensino Médio (ENEM) e a consequente bolsa do PROUNI não são suficientes para a manutenção nos estudos e finalização da graduação. Os alunos têm de administrar estudo, trabalho e família durante o curso superior. $O$ método utilizado foi qualitativo e exploratório. Foram pesquisados 13 alunos, que participaram de grupo focal e responderam questionário sociodemográfico. As informações foram tratadas por meio da análise de conteúdo de Bardin. Elencou-se as categorias: (1) Antes de entrar na graduação e (2) Durante a graduação. Em relação à primeira categoria, os resultados indicaram, principalmente, dificuldades provenientes das famílias dos estudantes, que, em sua maioria, não os apoiavam para cursar a graduação, incentivando-os a seguir a mesma ocupação dos genitores. Já na segunda categoria estavam presentes majoritariamente dificuldades financeiras e de relacionamento, tanto com pares quanto com professores. Os participantes afirmaram que, apesar das dificuldades, o fato de ter planejamento, esforço e determinação para concretizar um curso de graduação pode fazer a diferença nas suas perspectivas de vida futura.
ABSTRACT I The aim of this research was to know difficulties to attend undergraduate in students with full scholarship from Programa Universidade para Todos (PROUNI) from a private university in Rio Grande do Sul/Brazil. The idea for this research came from that Exame Nacional do Ensino Médio (ENEM) approval and the consequent PROUNI scholarship are not sufficient for the maintenance in the studies and completion of the graduation. Students must administer study, work, and family during college. The method used was qualitative and exploratory. Thirteen students were participants of this study, who participated in a focus group and answered a sociodemographic questionnaire. Two categories were listened: (1) Before entering the graduation and (2) During graduation. Regarding the first category, the results indicated, mainly, difficulties coming from the families of the students, who, for the most part, did not support them to attend the graduation, encouraging them to follow the same occupation of their parents. In the second category were present mainly financial and relationship difficulties, both with peers and with teachers. The participants stated that, despite difficulties, having planning, effort and determination to complete an undergraduate course can make a difference in their future life prospects.

KEYWORDS: Graduate students; Higher education; Educational programs.

PALAVRAS-CHAVE: Estudantes universitários; Ensino Superior; Programas educacionais. 


\section{Introdução}

Muitos jovens brasileiros apresentam expectativa de cursar uma graduação, mas seguidamente esse desejo é barrado por obstáculos culturais e econômicos, especialmente em jovens provenientes de classes socioeconômicas desfavorecidas (Sobrosa, Santos, Oliveira, \& Dias, 2014). Isto acontece porque, com frequência, eles não possuem condições de ensino de qualidade para competir por vagas da educação superior pública em igualdade com os indivíduos de poder aquisitivo mais elevado. Neste caso, entende-se que um ensino de qualidade está relacionado aquele que prepara crianças, jovens e adultos para ter possibilidades concretas de obter informações e aprendizagens para enfrentar reivindicações da sociedade e do mundo atual (Mendes, 2010). Além disso, a maioria não apresenta recursos financeiros para arcar com as despesas de cursar uma graduação em universidade privada (Oliveira, Pinto, \& Souza, 2003).

Diante dessa realidade, o governo federal brasileiro institucionalizou, em 2005, a partir da lei 11.096 , - Programa Universidade para Todos (PROUNI). Esse programa foi criado com o intuito de beneficiar estudantes de baixa renda por meio do ingresso em um curso de graduação e a consequente conquista de uma profissão (Lei n. 1 1.096, 2005). O PROUNI possibilita que jovens provenientes de classes socioeconômicas desfavorecidas recebam bolsas de estudos em Instituições de Ensino Superior (IES) privadas, as quais ganham isenção de impostos em troca da concessão dessas bolsas (Limena, Rodrigues, Petraglia, \& Almeida, 2011).

Sabe-se que conquistar uma vaga no ensino superior gera sentimentos de realização e alegria para a maioria dos jovens. Contudo, o ingresso em uma IES possivelmente é uma das mudanças mais difíceis que os jovens se deparam no decorrer de suas vidas (Feldt, Graham, \& Dew, 2011). O ambiente acadêmico é permeado por mudanças que requerem do estudante que ele corresponda às cobranças de bom desempenho e se adapte às novas regras da instituição na qual está se inserindo e às pessoas com ela envolvida, como colegas, professores e funcionários. As primeiras demandas universitárias burocráticas (confirmação de vaga, matrícula, cadastro na biblioteca e no Restaurante Universitário),
○ nível de exigência das aulas, ○ grande volume de leituras e a cobrança de trabalhos podem ser percebidas como bruscas, o que faz com que alguns discentes se sintam perdidos, confusos e inseguros frente ao cotidiano universitário (Teixeira, Dias, Wottrich, \& Oliveira, 2008).

Essa confusão e insegurança, juntamente com as alterações no círculo de relacionamentos familiares e sociais, podem desencadear situações de crise entre os universitários. $O$ início da vida adulta, que usualmente ocorre durante a entrada na universidade, tende a ser uma fase do ciclo vital propícia para o surgimento de transtornos mentais (Neves \& Dalgalarrondo, 2007). A quantidade de universitários que se encontram em sofrimento psíquico é cada vez maior, além de haver um aumento da gravidade dos problemas mentais apresentados por essa população (Hyun, Quinn, Madon, \& Lustig, 2006).

É comum que universitários sejam acometidos por distúrbios não psicóticos, isto é, transtornos mentais menores, os quais englobam sintomas ansiosos, depressivos e somáticos (Carneiro \& Baptista, 2012; Cerchiari, Caetano, \& Faccenda, 2005; Neves \& Dalgalarrondo, 2007), além de apresentarem estresse e disfunção alimentar (Sulkowski \& Joyce, 2012). Ademais, alguns estudantes podem recorrer ao uso e abuso de drogas lícitas e/ou ilícitas para enfrentar as dificuldades advindas da entrada na universidade (Assis \& Oliveira, 2010).

Além das dificuldades inerentes ao processo de ingresso em uma universidade, frequentemente os alunos PROUNIstas se deparam com problemas financeiros. Apesar do PROUNI propiciar a inclusão acadêmica de jovens desfavorecidos economicamente, que de outra forma não teriam condições de ingressar em uma IES particular, esse programa, por si só, não garante a continuidade dos estudos desses alunos. Além da mensalidade, outros aspectos são indispensáveis para a continuação da graduação, por exemplo, livros didáticos, transporte, moradia e alimentação (Souza, 2011). Para arcar com essas despesas, a maioria dos alunos PROUNIstas precisam trabalhar. Muitos acabam evadindo de seus cursos por não conseguirem conciliar a jornada acadêmica com o trabalho (Oliveira et al., 2003). Almeida, Marinho-Araújo, Amaral, e Dias (2012) destacam que, apesar de não haver estatísticas seguras 
para demonstrar isto, as taxas de abandono e insucesso em concluir o ensino superior penalizam os alunos de estratos sociais menos favorecidos, diante da dificuldade dos horários dos cursos diurnos, ou de conciliação dos estudos com alguma forma de trabalho, ou mesmo pela necessidade de escolher um curso que não seria a sua primeira escolha. Assim, mesmo diante do aumento das oportunidades de acesso ao ensino superior para um número cada vez maior de estudantes, o êxito na graduação ainda se encontra diferenciado por classe social.

Devido a essas adversidades são crescentes os casos de insucesso de alunos no ensino superior. $O$ insucesso pode ser manifestado por altos índices de absenteísmo, disciplinas em atraso, mudanças de curso, evasão de universidades e aumento da procura de universitários e recém-formados por processos de aconselhamento de carreira (Bardagi \& Hutz, 2012 ; Igue, Bariani, \& Milanesi, 2008). A falta de maior conhecimento sobre o que é a universidade e o que esperar dela, tanto em termos acadêmicos quanto pessoais, são fatores que podem agravar as dificuldades de adaptação a esse novo contexto (Teixeira et al., 2008) e fazer com que os discentes tenham dificuldade em superar os obstáculos que se apresentam para eles.

Conforme mencionado, os alunos PROUNIstas podem enfrentar muitas adversidades para ingressar, permanecer e concluir uma graduação. Contudo, essas dificuldades ainda são pouco conhecidas. Por isto, este artigo objetivou conhecer as dificuldades para cursar uma graduação em estudantes bolsistas do Programa Universidade para Todos (PROUNI), com bolsa integral, de uma universidade privada do Rio Grande do Sul/Brasil.

\section{Método}

A pesquisa apresenta método qualitativo, de caráter exploratório e trata-se de um estudo transversal. Segundo Turato (2008), a pesquisa qualitativa tem por interesse analisar as significações que o objeto de estudo (indivíduo ou grupo) confere aos fenômenos da natureza nos quais está envolvido.
A pesquisa contou com a participação de 13 estudantes bolsistas de graduação integrais do PROUNI (cinco homens e oito mulheres) provenientes de uma universidade privada localizada no Rio Grande do Sul/Brasil. Foram critérios de inclusão os alunos com bolsa PROUNI de 100\% (preferencialmente desde o início da graduação), serem maiores de 18 anos, estudarem na modalidade presencial e estarem regularmente matriculados na cidade sede da Universidade. Realizar estágio ou ter alguma atividade remunerada não foram considerados critérios de exclusão.

Os estudantes bolsistas do PROUNI participantes desta pesquisa estavam matriculados em uma universidade que, na época da pesquisa, contava com mais de 3.700 alunos com bolsas parciais e integrais (50\% ou 100\%) do Governo Federal. Em março de $2014,2.687$ alunos tinham bolsa de 100\% e 1.001 alunos bolsa parcial, segundo dados da Diretoria de Ação Social (DAS) da Instituição. No segundo semestre de 2014, 2.795 alunos contavam com bolsa integral e 906 alunos com bolsa parcial. A Universidade pesquisada, por questões relacionadas ao planejamento estratégico e à concessão da filantropia, passou a conceder, a partir de 2015, apenas bolsas de estudo integrais.

A mantenedora da Instituição, atenta às dificuldades dos estudantes bolsistas PROUNlstas, criou o Programa de Inclusão Educacional e Acadêmica (PIEA) no ano de 2010. Esse programa é destinado aos alunos com bolsa integral do PROUNI, e tem como objetivo qualificar a aprendizagem pela construção do conhecimento para a melhoria do desempenho acadêmico e a qualidade de vida dos estudantes. O programa disponibiliza apoio financeiro, pedagógico, psicológico e social. O programa oferece semestralmente auxílio financeiro para transporte e vale alimentação, compatível com os gastos mínimos necessários para auxiliar a prover estes custos, para mais de 300 alunos PROUNIstas integrais. Estes alunos devem ter uma renda mensal de até um salário mínimo e para ganhar o vale alimentação devem vir direto do trabalho ou realizar duas atividades acadêmicas no mesmo dia. $\bigcirc$ auxílio transporte era calculado por aluno, de acordo com os ônibus que utilizavam para se deslocar até a universidade. $O$ PIEA é destinado tão somente aos alunos com bolsa integral PROUNI, conforme disponibilidade or- 
çamentária por tratar-se de uma liberalidade institucional. Ele é concedido a partir da entrega da documentação e de uma análise socioeconômica, realizada por uma equipe composta por assistentes sociais, quando são identificadas vulnerabilidades sociais e econômicas.

O primeiro contato foi com a DAS da Universidade pesquisada, a qual autorizou a pesquisa com alunos PROUNIstas. Foi realizado levantamento de quantos alunos PROUNIstas integrais preenchiam os critérios de inclusão e também quantos recebiam o benefício do PIEA. Posteriormente, foi realizado um sorteio separado para cada grupo: o primeiro se tratou de um grupo de bolsistas que recebiam benefícios do PIEA e o segundo que não recebiam esse benefício. Nessa ocasião, foi utilizada uma tabela de números aleatórios para sortear os alunos participantes dos dois grupos focais. A partir do sorteio, foram enviados e-mails convidando os alunos a participarem da pesquisa. Após, foi realizado contato telefônico reforçando o convite para a pesquisa e explicando a importância da mesma. No total, 16 alunos bolsistas aceitaram participar da pesquisa e 13 compareceram nos dias de coleta de informações.

Os bolsistas participaram de grupo focal. Foram desenvolvidos dois grupos focais: (1) bolsistas integrais do PROUNI que recebiam benefício do PIEA e (2) bolsistas integrais do PROUNI que não recebiam benefício do PIEA. Cada grupo foi composto por sete e seis alunos, respectivamente. Os grupos focais apresentaram duração de uma hora e 20 minutos cada. Antes dos grupos, foi realizado contrato de confidencialidade e sigilo em relação ao que seria tratado nos grupos e os alunos foram informados que os resultados seriam apresentados de forma genérica, sem nomes divulgados. Em ambos houve filmagem de áudio e vídeo, e também a participação de uma observadora (graduanda em Psicologia e assistente de pesquisa), a qual realizou a transcrição dos dados. Os grupos ocorreram nas dependências da Universidade, em horário vespertino. Os grupos focais seguiram o mesmo roteiro, que foi composto por questões norteadoras a respeito do processo de escolha pelo curso, da entrada na Universidade e das vivências/experiências na IES. Foram questionadas as dificuldades frente à opção por fazer uma graduação, a vivência na Instituição, a interferência desses fatores na vida e na saúde dos alunos PROUNIstas. Ressalta-se que, na análise das informações, não se encontrou diferenças expressivas nos dois grupos focais e, a partir disto, na apresentação dos resultados deste artigo, entendeu-se os grupos como um único grupo, não fazendo distinção entre aqueles que recebiam o benefício do PIEA e os que não recebiam.

Antes de iniciar as discussões, os participantes responderam um questionário sociodemográfico, o qual objetivou pesquisar dados gerais de identificação (nome, idade, estado civil, número de filhos, número de créditos concluídos, cidade natal, cidade onde reside); se o aluno trabalhava ou estagiava (dentro ou não de sua área de estudo), se tinha pessoas significativas na sua vida e, em caso afirmativo, quem eram elas. Também abordou temas sobre a satisfação com o curso escolhido; se participava de atividade voluntária e com quem residia.

Este projeto de pesquisa foi encaminhado ao Comitê de Ética da Universidade onde foi realizada a pesquisa para avaliação e recebeu a aprovação de número 847.340 (CAAE 36915814.2 .0000 .5344 ). Foram observados todos os procedimentos éticos para pesquisa com seres humanos, seguindo as resoluções de números 466/2012 (Resolução $n^{\circ}$ 466, 2012) e 016/2000 (Resolução n. 016/2000, 2000). A coleta de informações, somente ocorreu após a aprovação do projeto. Nos dias de coleta, os participantes leram e assinaram o Termo de Consentimento Livre e Esclarecido (TCLE) antes da realização do grupo focal. Foi combinado que o pesquisador disponibilizaria o link com o acesso da pesquisa concluída.

Para análise dos dados, considerando a totalidade das transcrições e registros dos dois grupos focais, foi utilizada a técnica de análise de conteúdo de Bardin (1977), com pré-análise, exploração do material e tratamento de resultados. Primeiramente, foi realizada uma leitura de todo o material para identificar ideias contidas. No segundo momento, fez-se uma lista de tópicos contidos no material. Na qual, foram elencadas categorias a posteriori definidas a partir do objetivo e do conteúdo relatado nos grupos focais. Nesta parte, utilizaram-se as regras de categorias homogêneas, excludentes e exaustivas. Depois se buscou organizar os tópicos nas categorias, voltando ao texto 
para marcá-los e verificando se novas categorias apareceriam. Por último, analisou-se as categorias, buscando interpretar o material, nomeando elas, estabelecendo relações com a realidade estudada e o aprofundando de conexões das ideias, considerando o objetivo do estudo.

\section{Resultados}

grupo de estudantes bolsistas do PROUNI foi composto por 8 mulheres e 5 homens, com idades entre 19 e 40 anos. Os cursos dos alunos pesquisados foram: Arquitetura e Urbanismo; Ciência da Computação; Direito; Economia; Engenharia Civil; Letras; Logística; Nutrição; Psicologia e Publicidade e Propaganda. Todos os alunos se declararam solteiros e naturais do RS e dois alunos informaram que tinham filhos (um filho cada).

Com relação ao período no curso, os alunos se encontravam do segundo ao sétimo semestre. No que se refere ao turno que estudavam, oito alunos informaram frequentar totalmente o período noturno, quatro alunos mais noturno que diurno e um aluno mais diurno que noturno.

Seis alunos faziam estágio e / ou trabalham, variando a carga horária de 20 a 40 horas semanais. $\mathrm{Na}$ pergunta se trabalhavam dentro da área de atuação do seu curso, um aluno não respondeu, oito responderam sim e quatro não. Dois alunos participavam de pesquisa de Iniciação Científica na universidade.

Com relação à satisfação com o curso escolhido, foi elaborada uma pergunta, através de uma escala tipo likert com variação de zero a dez, para perguntar sobre o grau de satisfação com o curso escolhido, visto que que nem todos os alunos que recebem bolsa PROUNI conseguem ser contemplados com a sua primeira escolha. Os graus de satisfação obtidos variaram de sete a dez. Três alunos informaram o valor dez. Quatro alunos participam de atividade voluntária. Todos os alunos informaram que têm pessoas significativas que podem contar na maioria das situações diárias. Foram citados namorados (as), noivo, filho, mãe, irmãos, tios, amigos, pai e família. Três alunos moravam apenas com a mãe.
Apenas um aluno morava sozinho. Os outros citaram que residiam com pai e filho, pais e mãe, e irmãos.

Os resultados foram organizados em categorias e subcategorias. As categorias foram definidas de acordo com os objetivos e também foram produzidas a partir dos relatos obtidos nos grupos focais, as quais serão apresentadas nesse tópico juntamente com falas selecionadas.

\section{Antes de entrar na graduação}

Nesta categoria, foram escolhidas questões iniciais que poderiam dificultar tanto a opção por cursar uma graduação bem como a entrada na universidade. Então foram levantadas as seguintes subcategorias: 1) falta de apoio e/ou incentivo dos pais; 2) falta de referências dos pais; 3 ) estímulo para que continuem na mesma atividade dos pais; 4) escola pública fraca e 5) outras dificuldades (financeira, gravidez na adolescência e preconceito com as licenciaturas).

Na subcategoria "falta de apoio e/ou incentivo dos pais", os alunos comentaram que a falta de apoio dos pais para dar continuidade aos estudos pode interferir negativamente na escolha por um curso superior, influenciada na maior parte pela baixa escolaridade dos pais:

[...] mas a minha mãe, se eu fosse um operador de caixa de um mercado, ela estaria feliz. Minha mãe nunca me incentivou a estudar."

Não cresci com o sonho de fazer faculdade, na verdade, esse foi um processo gradativo. Na verdade, a minha familia nunca teve essa cultura de crescer, ou quando criança, "bah, de repente tu faz uma faculdade". Eu nunca tive essas doutrinas, eu nunca recebi esse tipo de ensinamento.

Na subcategoria seguinte, "falta de referências dos pais", os filhos elencaram as dificuldades dos pais os ajudarem no processo de escolha, pois os mesmos não têm referência do que significa uma graduação e, muitas vezes, não podem contribuir com informações sobre o dia a dia em uma universidade.

Eu tava com muita dúvida porque a gente não tem muito conhecimento sabe. $E$ quando foi... ninguém tinha 
da minha família uma noção, então não sabia o que que tinha dentro daquele curso, o que que ele aprendia.

[...] mas eles (pais) não entendem muito de como funciona uma faculdade. Esses tempos o meu pai perguntou se a gente tinha as mesmas aulas que a gente tinha na escola aqui, só que um pouco mais difícil.

Na terceira subcategoria, "estímulo para que continuem na mesma atividade dos pais", os pais valorizam mais a questão do trabalho do que o estudo, ou mesmo que os filhos continuem a mesma atividade profissional dos progenitores:

[...] porque os meus pais eles têm a formação do ensino básico e sempre foi aquela questão da cultura de trabalhar mesmo, desde o início sempre trabalhar.

A gente falava pros meus pais, eu e a minha irmã, sobre fazer faculdade, sobre como pagar ela, porque a gente sabia que era bem caro. E eles falavam que a gente não ia precisar, que a gente podia trabalhar com eles ou alguma coisa do tipo.

Na quarta subcategoria, "escola pública fraca", os alunos demonstram que vieram de um ensino fundamental e médio com algumas deficiências, salientando as dificuldades educacionais do país em oferecer um ensino público de qualidade:

Por ter feito um ensino fundamental público, depois a continuidade público, então quer dizer, eu nunca estudei numa escola particular. $E$ é difícil, a gente sabe as mazelas que o ensino está sofrendo no País.

O ensino médio é péssimo praticamente, não tem... é um modo de dizer claro... não tem cobrança.

Na quinta e última subcategoria, "outras dificuldades", os PROUNIstas abordaram questões (financeira, gravidez na adolescência e preconceito com as licenciaturas) que podem interferir no processo de escolha por uma faculdade. São situações de vida que podem impactar significativamente na saúde dos alunos:

Eu não tinha acesso a internet e era meio difícil. Então ia lá na LanHouse e, às vezes, acabava o meu dinheiro e eu não conseguia (se inscrever no Enem).
Só que aos meus 14 anos eu tive um filho e daí acabou dificultando. Fiquei 2 anos sem estudar, e daí voltei pro ensino médio".

E aí quando eu decidi fazer licenciatura, meu pai ele me olhou assim, com uma cara, tu vai fazer licenciatura? Mas no começo de ir de uma ideia de fazer jornalismo pra fazer licenciatura, ele não gostou muito.

\section{Durante a graduação}

Nesta segunda categoria, os alunos bolsistas do PROUNI apontaram algumas dificuldades percebidas após a entrada na universidade e como tentam administrá-las durante o semestre letivo. A partir disto, emergiram as seguintes subcategorias: 1) exigência da faculdade é diferente do ensino médio; 2) administrar trabalho, estudo e vida pessoal; 3) manter-se economicamente durante o semestre; 4) dificuldade de construir vínculos com os pares; 5) relação com professores; 6) dificuldade pedagógica e 7) cansaço físico e possibilidade de desistência.

Na subcategoria "exigência da faculdade é diferente do ensino médio", os discentes discorreram sobre a mudança na forma de cobrança em relação ao ensino médio e como vivenciaram isso na entrada na graduação:

Pela questão de espera que eu entrei lá pela terceira semana, no primeiro semestre que eu fui fazer. Eu penei, eu cheguei assim nunca sabia nada o que que os caras tavam falando, falavam umas palavras em inglês

lá e eu o que que é isso. $E$ daí eu pensei também no primeiro semestre em desistir, eu não vou aguentar, vou desistir.

$E$ os professores sabem que tu trabalha, mas mesmo assim te dá um monte de trabalho e tu é obrigado a fazer no final de semana.

Na subcategoria "administrar trabalho, estudo e vida pessoal", os PROUNIstas contaram como lidam com as várias demandas durante a semana, sobretudo aqueles alunos que estudam e trabalham, e de que maneira administram isso na vida pessoal e familiar: 
A questão de não ter tempo pra nada, no semestre passado eu fiz 7 cadeiras, quase enlouqueci, quase enlouqueci minha família. Esse semestre eu tive que reduzir para 3, porque o choque lá em casa foi tão grande, que o meu filho rodou de ano.

É por isso que eu aprendi a escovar os dentes tomando banho. Não dá pra perder tempo pra nada, né. Tem que dormir quando tá no ônibus, tem que ler quando tá

no trem.

No meu caso é ter que conciliar porque eu sou obrigado a trabalhar, eu tenho que trabalhar porque eu sou o filho mais velho de 4 irmãos, dai então não tenho condições de ficar cursando uma faculdade sem trabalhar, mesmo tendo bolsa. Eu chego em casa agora só as 11 horas da noite e daí eu tenho que estudar alguma coisa e acabo indo dormir tarde, pra acordar as 7 horas de novo.

Na terceira subcategoria "manter-se economicamente durante o semestre", os PROUNIstas relatam a dificuldade de se sustentar financeiramente, apesar de terem a bolsa integral, e como a necessidade de ter que trabalhar influencia na sua qualidade de vida:

Eu deixei de vir a muita aula porque eu não tinha dinheiro pra passagem. $E$ ainda com filho, eu não recebo pensão do pai dele, então é só eu pra bancar - meu filho e para minha mãe, $R \$ 10,00$ de passagem faz falta no orçamento depois.

E aí agora eu tive que voltar (a trabalhar), estou como "CC" (cargo de confiança) na prefeitura porque infelizmente não deu, eu queria focar na faculdade, mas não consegui porque também tem as contas pra pagar. Infelizmente não dá pra viver só da faculdade.

Eu, às vezes, tenho que abrir mão de estudar um pouco pra trabalhar... eu moro sozinho em tese, mas eu pago aluguel e tudo, eu me sustento, então se eu não trabalho, eu não tenho como pagar aluguel, não

tenho como pagar comida, não tenho como pagar transporte... então eu, de uma certa forma, tenho que priorizar um pouco o trabalho... tipo $60 \%$ o trabalho

e $40 \%$ universidade. Eu sou um cara extremamente estressado porque é uma pressão assim... cara, eu tenho 22 anos e talvez não precisava ter esse pressão, mas não sei... eu não tenho escolha, né.
Na quarta subcategoria, "dificuldades em construir vínculos com os pares", os discentes comentaram sobre os obstáculos para fazer e manter as amizades durante a graduação. Isso também aparece na hora de recrutar um ou mais colegas para estudar junto:

Aqui tem 5 dias, daqui a pouco eu vou te encontrar num dia da semana só. Raramente a gente encontra colegas que façam 3 disciplinas conosco assim.

A gente não consegue pegar vínculo de amizade, porque nem todo mundo tem condições de fazer 5 , nem todo o mundo que consegue pegar as mesmas disciplinas para fazer a matrícula, então fica difícil. $E$ fica aquela coisa meio impessoal, às vezes, as pessoas olham pra ti e dizem: "tu tem uma cara de cheia". Não, não é, tu nem conhece essa pessoa ainda. Mas a gente quer, a gente gostaria de ter círculo de amizade e eu acho que isso faz parte da universidade também.

Uma coisa que eu acho importante e eu consigo raramente é tu ter colega pra ti estudar. Porque são 2 cabeças, 3 cabeças pensam melhor e com certeza se a gente tivesse isso, a gente iria melhor. Mesmo com todo esse nível de trabalho que a gente tem, esse cansaço enlouquecedor, se nós tivéssemos colegas para estudarmos juntos, seria bem melhor. Porque eu já tive nesse tempo, eu acho que uns 3,4 que eu pude estudar

junto e a coisa vai bem, as notas melhoram, o teu entendimento também. Porque é a aula e depois tu sai e aí tó sozinho, tá sozinho no mundo sabe, te vira.

Na quinta subcategoria "relação com professor", os PROUNlstas apontaram as dificuldades de alguns professores de se aproximarem dos alunos, sendo que há docentes que apresentam dificuldades para serem tolerantes e afetivos:

[...] mas, às vezes, tu pega uns professores que eles

te tratam como se tu tivesse Doutorado, como se tu soubesse tudo. Se tu pergunta, o cara te rechaça, como se tu fosse obrigado a saber. Ou daqui a pouco tu não elaborou uma pergunta correta, tu entendeu?

E o professor que tá lá ao invés de tornar a coisa mais fácil pra ti ou ser mais aconchegante, receptivo, não. Ele te coloca lá no teu lugar e tu tem que ir sozinha, tu tem que buscar sozinha. [...] Porque às vezes me representa que eles sonegam um pouco da informação porque daí daqui a pouco não é legal, esse ai já é um concorrente meu, sei lá eu. Eu não entendo, mas assim a soberba é grande. 
Na subcategoria, "dificuldade pedagógica", emergiram as preocupações dos alunos no entendimento e aprovação nas matérias, uma vez que pode refletir na perda da bolsa, pois os alunos têm que ter aprovação de, no mínimo, $75 \%$ por semestre nas atividades curriculares para a manutenção da bolsa:

Mas eu até tenho dificuldade a estudar assim, eu tenho muita dificuldade. Eu consigo entender a matéria, mas pra parar, sentar e estudar, eu não consigo. Eu tenho muita dificuldade, pra parar e estudar assim. Eu vou bem nas cadeiras, mas porque eu presto atenção na aula, uma coisa assim, mas pra parar e estudar eu tenho muita dificuldade.

No primeiro dia da prova eu disse ah é fácil, barbada, daí chega o grau $B$ e... Cheguei lá, não tá tranquilo, no grau B... bah, tá louco...

Na última subcategoria, "cansaço físico e possibilidade de desistência", as falas relataram o desgaste físico e que, em alguns momentos, a vontade de desistir aparece de maneira mais significativa:

É difícil tu pegar trem todo o dia pra ir pra P.A., esse translado cansa, que é uma loucura e não adianta tu querer estudar porque tu fica vendo uma coisinha passando assim... tu dispersa, tu não consegue prestar atenção na tua leitura, sabe. No trem tu vai de pé e cansa e daqui a pouco quando tá em casa tu quer...

Quando eu to em casa pra eu estudar, eu só quero dormir, é uma cama, fecha tudo e dormir sabe, dormir, porque é muito cansada, eu to cansada. $E$ às vezes tu não consegue colocar em dia os teus estudos porque precisa trabalhar, precisa se sustentar.

Da meia-noite à cinco ainda dá pra estudar e domingo dá pra dormir. Domingo é dia de dormir. Eu hiberno pelo menos.

É aquela desistência tipo momentânea que as coisas vão se acumulando assim e daí tu diz assim, dá vontade de mandar tudo pro alto. Porque eu não to mais conseguindo resolver as coisas, a minha vida, dá em todo o mundo, né.

\section{Discussão}

De modo geral, os participantes consideraram a opinião da família no momento da escolha pela profissão que pretendiam exercer, seja um curso superior ou não. A família pode influenciar positiva ou negativamente na opção de fazer um curso universitário. Em diversos casos, os pais, por não terem o conhecimento de outras realidades profissionais, acabam incentivando os filhos a continuarem na mesma atividade profissional desenvolvida por eles. Isso vai ao encontro da literatura sobre orientação profissional, uma vez que se sabe que a implementação de decisões de carreira é permeada por uma atuação direta ou indireta dos pais, seja por meio da relação que estabelecem com os filhos ou das atividades que desempenham (Carvalho \& Taveira, 2012).

Outra questão referente à família é a maior importância concedida pelos pais ao trabalho em detrimento do estudo. Nesse caso, os estudantes bolsistas PROUNIstas precisam, até certo ponto, enfrentar a família para estudar. Parece o diferencial entre um PROUNIsta que trabalha e estuda e um aluno regular, que também trabalha e estuda, é o papel da família como um desarticulador do desejo de estudar. É lógico pensar que isso pode ocorrer com outros grupos de alunos, mas nos PROUNlstas participantes deste estudo isso parece ser mais evidente.

Além das questões da família descritas anteriormente, os participantes estudaram durante o ensino médio no setor público, geralmente, de baixa qualidade e que não os preparou adequadamente para - ENEM e nem ofereceu uma base de conhecimentos suficiente para auxiliar no seguimento dos estudos, quando fazem essa opção. Fato é que se percebe que as escolas de ensino médio públicas não apresentam preocupações em relação aos instrumentos de seleção para o ingresso no ensino superior, enquanto que a escola particular trabalha intencionalmente nesse sentido (Ortega, 2001). Os professores do ensino médio tendem a incentivar a continuidade dos estudos, mas, às vezes, não conseguem desempenhar esse papel. A preparação para o ENEM seguidamente ocorre por esforço próprio e com pouco incentivo da família. 
Os jovens que são contemplados com a bolsa do PROUNI ficam muito satisfeitos pela conquista, pois não terão a preocupação inicial com as mensalidades escolares, mas, ao mesmo tempo, percebem que $a$ isenção desse custo não é o suficiente para a sua manutenção na universidade (Rocha, 2011). Os gastos diários para a sua sobrevivência no mundo acadêmico dependem muito do próprio estudante bolsista PROUNIsta. Eventualmente, a família auxilia, mas a obtenção de renda é de responsabilidade do mesmo. Para dar conta destes gastos, uma possibilidade é o aluno ingressar no mundo informal do trabalho, o que eles próprios chamam de "fazer bicos", ou executar atividades distantes da sua área de conhecimento. A realização de estágios (curriculares ou não obrigatórios) também é uma fonte de renda. Esta renda auxilia os PROUNIstas, mas também acaba exigindo um esforço significativo para administrar estudo e trabalho. Ao ter que lidar com essa realidade, a sobrecarga física e emocional pode ficar insuportável, e o estudante terá que fazer uma opção, conforme o relato de um dos participantes: "então eu, de uma certa forma, tenho que priorizar um pouco o trabalho... tipo $60 \%$ o trabalho e $40 \%$ universidade". Almeida et al. (2012) destacam que, no Brasil, os alunos mais novos com menor poder aquisitivo, que possuem bolsas de estudo ou não, tendem a frequentar cursos noturnos de IES privadas de rápida duração, muitas vezes não dispondo de tempo, espaço e condições apropriadas para estudar e têm dificuldades para conciliar o tempo de trabalho com as atividades acadêmicas e extra aula (extensão cultural, pesquisa, encontros científicos).

Em um estudo cujos participantes foram 132 PROUNlstas, Felicetti (2014) quantificou as dificuldades encontradas pelos egressos durante a vivência acadêmica nas seguintes subcategorias: dificuldade de material/tempo; dificuldades financeiras; dificuldade sócio-afetiva e dificuldade geográfica. Esses dados foram colhidos em uma universidade comunitária do Rio Grande do Sul e estão de acordo com as dificuldades que se sobressaíram nesta pesquisa. Ainda, segundo a pesquisadora, o percentual de PROUNIstas que trabalharam mais de quatro anos durante a graduação é alto e pode variar de aluno para aluno. A partir dessa análise, pode-se inferir que $O$ trabalhar, o estudar e o viver são concomitantes, isto é, não há separação entre essas ações; estudar é viver, e as conquistas do estudo têm efeito no trabalho e na vida social e se intercambiam.

A questão da sobrecarga e cansaço emergiu em várias falas. A realidade de agenda lotada com estágio e/ou trabalho (às vezes, os três turnos ocupados) foi uma constante no relato dos participantes. Para eles, estudar exige muito, e palavras como "enlouquecer", "estressado" adquirem um sentido de limite da resistência física e mental dos alunos. O aumento do sofrimento psíquico é uma realidade dos universitários (Hyun et al., 2006). Se o domingo é utilizado para "hibernar", pode indicar que há pouco tempo para o lazer ou mesmo para a prática de uma atividade física ou desestressante.

Os alunos que trabalham descrevem o desgaste que sofrem para conciliar estudo e trabalho. Ganhar a bolsa integral não é certeza de que a mesma será utilizada até o final do curso. É necessário um esforço considerável para manter a bolsa $(75 \%$ de aprovação nas atividades curriculares). $O$ preparo para as avaliações, provas e trabalhos em grupo são exemplos deste esforço fora da sala de aula. Isso fica evidenciado na seguinte fala de um participante: "E como a gente quer muito, a gente se vira nos 30 , né. A gente se vira nos 30 pra poder dar conta, então quer dizer, tu ganhou algo, tu tem que se movimentar pra poder, pra isso dar certo. Pra ter uma continuidade, início, meio e fim do curso". Percebe-se esforço físico e cognitivo dos participantes, pois, na maioria dos casos, eles tem de conciliar diversas atividades, daí a ideia de "dar conta". 0 estudo, para eles, não é só mais uma tarefa a ser cotidianamente cumprida, na citação acima o participante deixa claro que "tem que se movimentar para isso dar certo".

Quanto à presença de professores mais compreensivos no início do curso, isso pode ajudar os alunos no processo de adaptação dentro do contexto acadêmico. Professores mais exigentes e com pouca capacidade de entender a realidade menos favorável desses alunos contribui para a diminuição do bem-estar em sala de aula e, consequentemente, pode ser um fator para a desistência do curso. A importância do docente na permanência de discentes no ensino superior foi comprovada a partir de estudo realizado com oito estudantes evadidos de diferentes cursos de universidades públicas e priva- 
das do Rio Grande do Sul, o qual tinha o objetivo de compreender, a partir da visão desses alunos, quais aspectos contribuíram para o abandono da graduação. Os alunos relataram quase unanimemente a decepção com o tipo de vínculo estabelecido com os professores: mais distante, mais formal, com menos espaços de interação social, percepção de menor interesse pelas questões individuais do aluno. Essa percepção contrasta com a expectativa que os alunos tinham de manutenção dos vínculos de proximidade e proteção vivenciados na escola, - que repercutiu negativamente na avaliação que eles fizeram da integração à IES que frequentavam (Bardagi \& Hutz, 2012).

A duração dos cursos da graduação são de, no mínimo, de quatro a cinco anos. Esse prazo é difícil de ser cumprido pelos alunos (PROUNIstas e não PROUNIstas), o estudo de Felicetti (2014) apontou que $46,27 \%$ dos egressos $(n=134)$ do PROUNI realizaram o curso em tempo acima do padrão. A ampliação do tempo de formatura implica diretamente na perspectiva de investimento pessoal de médio a longo prazo, pois os alunos são obrigados a viver no limite por um tempo maior que o previsto. Isto também pode afetar a qualidade de vida dos alunos.

Outra dificuldade comentada pelos alunos é formar uma turma e constituir laços de amizade, que poderiam ajudar a apoiar nos momentos difíceis, além de ajudar nos trabalhos em grupo. Como os alunos não têm muito tempo disponível, encontrar um horário fora da sala de aula se torna uma atividade difícil. Sabe-se que os vínculos com os pares podem colaborar para o bem-estar dos jovens a partir da criação de uma rede de suporte emocional fora da família (Rosin, 2012) por meio do apoio em casos de dificuldade e do compartilhamento de expectativas, interesses, problemas e experiências (Teixeira et al., 2008). Neste sentido, a turma desempenha a função de apoio afetivo e acadêmico para auxiliar os estudantes em situações problemáticas (Teixeira et al., 2008). Além disso, ela contribui para a construção da identidade profissional dos alunos (Teixeira et al., 2008), uma vez que os discentes tendem a associar informações sobre o curso, os colegas e a instituição com a profissão, de forma a compor o perfil do profissional que desejam ser (Bardagi \& Hutz, 2012). Observa-se que os pares auxiliam na superação dos obstáculos acadêmicos por meio dos apoios afetivo (conversas sobre as vivências acadêmicas positivas e negativas, troca de experiências e apoio na resolução de problemas) e instrumental (estudos em conjunto, discussões e debates de textos, empréstimos de materiais e explicações da matéria por aqueles que dominam o conteúdo) (Santos, Oliveira, \& Dias, 2015).

Pode-se analisar, nesta pesquisa, que há diversas dificuldades presentes durante a vida acadêmica dos estudantes PROUNlstas, antes mesmo de pensarem na possibilidade de cursar uma universidade. Costa e Ferreira (2017) indicaram uma taxa de $10,4 \%$ de alunos que não conseguiram concluir $\circ$ curso. $O$ limite entre $\circ$ que aluno consegue suportar efetivamente e o que ele não consegue (nesse caso desistindo do seu sonho de conclusão de uma graduação) é muito tênue. Existem as idiossincrasias de cada um e como o indivíduo lida com as dificuldades do dia a dia.

\section{Considerações Finais}

Este artigo objetivou conhecer as dificuldades para cursar uma graduação em estudantes bolsistas do Programa Universidade para Todos (PROUNI), com bolsa integral, de uma universidade privada do Rio Grande do Sul/Brasil. As dificuldades podem começar antes mesmo do ingresso em uma Instituição de Ensino Superior. A família tem um papel importante para o estudante, dando pouco ou nenhum apoio para a continuidade nos estudos e se estender para a dificuldade de fazer a inscrição no ENEM e continuar com a fase inicial de adaptação em um ambiente universitário. $O$ ENEM possibilitou a entrada de inúmeros jovens nas universidades privadas, os quais teriam pouco ou nenhum acesso ao ensino superior. A dificuldade seguinte é a manutenção desses jovens nas IES que ingressaram.

O acesso às IES privadas foi um passo muito significativo para dar início ao conhecimento acadêmico, mas exige um esforço elevado para que os PROUNlstas consigam manter a bolsa integral durante a permanência no ensino superior. Em um contexto ideal, a melhora na qualidade do ensino fundamental e médio auxiliaria ainda mais os jovens a entrar na universidade. Dentro deste ideal, o apoio incon- 
dicional dos pais ou pessoas significativas seria um segundo passo para dar mais segurança aos PROUNlstas. Um terceiro aspecto ideal seria a possibilidade dos PROUNIstas terem tempo para se dedicar aos estudos integralmente. Infelizmente, essa conjugação ainda não é possível dentro da nossa realidade socioeconômica brasileira atual.

As informações obtidas nesta pesquisa contribuem com o conhecimento para a área de investigação da população estudada, porque o PROUNI existe há cerca de 10 anos e ainda há escassez de publicação sobre o assunto. Considera-se que o número de participantes foi uma limitação da pesquisa, pois possibilitou conhecer uma realidade local e de um pequeno grupo de PROUNIstas. Espera-se que este estudo incentive a realização de pesquisas com o grupo em foco e que esses resultados possam contribuir para pensar e proporcionar, cada vez mais, um serviço de qualidade, tanto na orientação quanto na acolhida aos PROUNIstas.

Percebe-se que o aluno gostaria de estreitar ainda mais os laços com os professores, portanto, uma das soluções que este estudo oferece é solicitar auxílio aos docentes a fim de que eles identifiquem alunos com alguma dificuldade. Os docentes são a linha de frente da universidade e estão na convivência diária com os alunos, sendo possível o aluno PROUNlsta pedir ajuda quando achar necessário.

Para finalizar, é preciso entender que as dificuldades dos alunos PROUNIstas são similares aos alunos de baixa renda que não possuem bolsa integral. Por exemplo, a falta de recursos para o pagamento de transporte público, a falta de tempo para o estudo em função do trabalho e o cansaço são questões que os alunos regulares também podem enfrentar. No entanto, para os PROUNIstas, outros aspectos foram descobertos. Destaca-se a necessidade do enfrentamento perante a família da opção pelo estudo, já que trabalhar seria mais interessante na visão dos pais, além da responsabilidade com o próprio estudo, pois há uma exigência de notas para a manutenção da bolsa. Também na relação com o trabalho o estudo está presente, conforme relatado, o chefe precisa ser compreensivo na medida em que deve entender a necessidade do PROUNIsta. Neste sentido, o próprio aluno se coloca em uma condição que o diferencia dos outros. Essa condição, contudo, não é a do aluno carente em si, mas daquele que, apesar da carência financeira, enfrenta desafios para poder estudar, buscando alcançar uma melhor qualificação acadêmica.

Para concluir, espera-se que este estudo possa ter trazidos contribuições para se pensar na necessidade de buscar melhorias e de um acompanhamento mais próximo na Graduação, buscando a efetivação do curso superior em estudantes bolsistas do PROUNI. Destaca-se entre estas ações a necessidade de uma escuta qualificada, de apoio emocional e, por vezes, até financeiro aos alunos PROUNltas que buscam a possibilidade de concluir o curso superior, apesar das dificuldades que encontram para superar uma condição de vida desfavorável para isto, podendo assim almejar um futuro melhor.

\section{Contribuições dos autores}

César Leonardo Karnal participou da concepção da pesquisa, coordenou a coleta de dados, realizou a análise qualitativa dos dados da pesquisa, a interpretação dos resultados e a redação do artigo científico. Janine Kieling Monteiro participou da análise qualitativa dos dados, realizou a supervisão da equipe e a redação do artigo. Grace Oliveira dos Santos participou da coleta de dados da pesquisa, da análise qualitativa dos dados da pesquisa, e da redação do artigo. Anelise Schaurich dos Santos participou da revisão de literatura, da interpretação dos dados, da redação e do encaminhamento do artigo científico.

\section{Conflitos de interesses}

Nenhum conflito financeiro, legal ou político envolvendo terceiros (governo, empresas e fundações privadas, etc.) foi declarado para nenhum aspecto do trabalho submetido (incluindo mas não limitandose a subvenções e financiamentos, conselho consultivo, desenho de estudo, preparação de manuscrito, análise estatística, etc).

\section{Referências}

Almeida, L., Marinho-Araújo, C. M., Amaral, A., \& Dias, D. (2012). Democratização do acesso e do sucesso no ensino superior: uma reflexão a partir das realidades de Portugal e do Brasil. Avaliação: Revista da Avaliação da Educação Superior, 17(3), 899920. Recuperado de http://www.scielo.br/pdf/ aval/v17n3/a14v17n3.pdf. doi: 10.1590/S141440772012000300014 
Assis, A. D., \& Oliveira, A. G. B. (2010). Vida universitária e saúde mental: atendimento às demandas de saúde e saúde mental de estudantes de uma universidade brasileira. Cadernos Brasileiros de Saúde Mental, 2(4-5), 159-177. Recuperado de http://incubadora. periodicos.ufsc.br/index.php/cbsm/article/ view/1113/1305

Bardagi, M. P., \& Hutz, C. S. (2012). Rotina acadêmica e relação com colegas e professores: impacto na evasão universitária. Psico, 43(2), 174-184. Recuperado de http://revistaseletronicas.pucrs.br/ojs/index.php/ revistapsico/article/view/7870/8034

Bardin, L. (1977). Análise de conteúdo. São Paulo: Martins Fontes.

Carneiro, A. M., \& Baptista, M. N. (2012). Saúde geral e sintomas depressivos em universitários. Salud \& Sociedad, 3(2), 166-178. Recuperado de http:// pepsic.bvsalud.org/pdf/salsoc/v3n2/v3n2a04.pdf

Carvalho, M., \& Taveira, M. C. (2012). A implementação de decisões vocacionais: revisão da literatura. Revista Brasileira de Orientação Profissional, 13(1), 27-35. Recuperado de http://pepsic.bvsalud.org/pdf/rbop/ v13n1/05.pdf

Cerchiari, E. A. N., Caetano, D., \& Faccenda, O. (2005). Prevalência de transtornos mentais menores em estudantes universitários. Estudos de Psicologia, 10(3), 413-420. Recuperado de http://www.scielo.br/pdf/ epsic/v10n3/a10v10n3.pdf. doi: 10.1590/S1413$\underline{294 \times 2005000300010}$

Costa, D. D., \& Ferreira, N. B. (2017). O PROUNI na educação superior brasileira: indicadores de acesso e permanência. Avaliação: Revista da Avaliação da Educação Superior, 22(1), 141-163. Recuperado de http://www.scielo.br/pdf/aval/v22n1/19825765-aval-22-01-00141.pdf. doi: 10.1590/s1414$\underline{40772017000100008}$

Feldt, R. C., Graham, M., \& Dew, D. (2011). Measuring Adjustment to College: Construct Validity of the Student Adaptation to College Questionnaire. Measurement and Evaluation in Counseling and Development, 44(2), 92-104. Recuperado de http://journals.sagepub.com/ doi/abs/10.1177/0748175611400291. doi: $\underline{10.1177 / 0748175611400291}$

Felicetti, V. L. (2014). Comprometimento do aluno PROUNI: acesso, persistência e formação acadêmica. Revista Brasileira de Estudos Pedagógicos, 95(241), 526543. Recuperado http://www.scielo.br/pdf/ rbeped/v95n241/05.pdf. doi: 10.1590/S2176$\underline{6681 / 301911955}$
Hyun, J. K., Quinn, B. C., Madon, T., \& Lustig, S. (2006). Graduate Student Mental Health: Needs Assessment and Utilization of Counseling Services. Journal of College Student Development, 47(3), 247-266. Recuperado de https://eric.ed.gov/?id=EJ743920.

Igue, E. A., Bariani, I. C. D., \& Milanesi, P. V. B. (2008). Vivência acadêmica e expectativas de universitários ingressantes e concluintes. Psico-USF, 13(2), 155 164. Recuperado de http://www.scielo.br/pdf/ pusf/v13n2/v13n2a03.pdf. doi: 10.1590/S1413$\underline{82712008000200003}$

Lei $n^{\circ} 11.096$, de 13 de janeiro de 2005. Institui o Programa Universidade para Todos - PROUNI. Recuperado de http://www.planalto.gov.br/ccivil_03/_ato20042006/2005/lei/11 1096.htm

Limena, M. M., Rodrigues, M. L., Petraglia, I., \& Almeida, C. (2001). PROUNI e inclusão social. São Paulo: Xamã.

Mendes, M. S. S. (2010). O ideário da qualidade de ensino na escola pública: uma leitura crítica sob a ótica da Psicologia escolar. Psicologia, Ensino \& Formação, 1(2), 61-71. Recuperado de: http://pepsic.bvsalud.org/ pdf/pef/vln2/v1n2a06.pdf

Neves, M. C. C., \& Dalgalarrondo, P. (2007). Transtornos mentais auto-referidos em estudantes universitários. Jornal Brasileiro de Psiquiatria, 56(4), 237-244. Recuperado de http://www.scielo.br/pdf/jbpsiq/ v56n4/a01v56n4.pdf. doi: 10.1590/S0047. $\underline{20852007000400001}$

Oliveira, M. C. S. L., Pinto, R. G., \& Souza, A. S. (2003). Perspectivas de futuro entre adolescentes: universidade, trabalho e relacionamentos na transição para a vida adulta. Temas em Psicologia, $11(1)$, 1627. Recuperado de http://pepsic.bvsalud.org/pdf/ $\mathrm{tp} / \mathrm{v} 1 \ln 1 / \mathrm{v} 1 \mathrm{ln} 1 \mathrm{a03} . \mathrm{pdf}$

Ortega, E. M. V. (2001). O Ensino médio público e o acesso ao ensino superior. Estudos em Avaliação Educacional, 23, 153-179. Recuperado http://publicacoes.fcc. org.br/ojs/index.php/eae/article/view/2213. doi: $10.18222 /$ eae02320012213

Resolução n. 016/2000, de 20 de dezembro de 2000. Dispõe sobre a realização de pesquisa em psicologia com seres humanos. Recuperado de http://www.fiocruz.br/ biosseguranca/Bis/manuais/qualidade/Cfp 16-00.pdf

Resolução n. 466, de 12 de dezembro de 2012 . Aprova normas regulamentadoras de pesquisas envolvendo seres humanos. Recuperado de http://bvsms. saude.gov.br/bvs/saudelegis/cns/2013/ res0466_12_12_2012.html 
Rocha, M. A. M. (2011). Processo de inclusão ilusória: o jovem bolsista universitário. Jundiaí: Paco Editorial.

Rosin, A. B. (2012). Bem-estar subjetivo, personalidade e vivências acadêmicas em estudantes universitários (Monografia de especialização). Universidade Federal do Rio Grande do Sul, Porto Alegre, RS, Brasil. Recuperado de http://www.lume.ufrgs.br/ handle/10183/39075

Santos, A. S., Oliveira, C. T., \& Dias, A. C. G. (2015). Características das relações dos universitários e seus pares: implicações na adaptação acadêmica. Revista Psicologia: Teoria e Prática, 17(1), 150-163. Recuperado de http://pepsic.bvsalud.org/pdf/ ptp/v17n1/13.pdf. doi: 10.15348/1980-6906/ psicologia.v17n1p150-163

Sobrosa, G. M. R., Santos, A. S., Oliveira, C. T., \& Dias, A. C. G. (2014). Perspectivas de futuro profissional para jovens provenientes de classes socioeconômicas desfavorecidas. Temas em Psicologia, 22(1), 223-234. Recuperado de http://pepsic.bvsalud.org/pdf/tp/ v22n1/v22n1 a 17.pdf. doi: 10.9788/TP2014.1-17

Souza, L. E. R. (2011). O PROUNI como política pública de ação afirmativa: uma análise do impacto sociocultural na trajetória de egressos, oriundos das camadas populares do PROUNI da PUC-MG (Dissertação de mestrado). Pontifícia Universidade Católica de Minas Gerais, Belo Horizonte, MG, Brasil.

Sulkowski, M. L., \& Joyce, D. J. (2012). School psychology goes to college: the emerging role of school psychology in college communities. Psychology in the Schools, 49(8), 809-815. Recuperado de https:// onlinelibrary.wiley.com/doi/pdf/10.1002/pits.21634. doi: $10.1002 /$ pits.21634

Teixeira, M. A. P., Dias, A. C. G., Wottrich, S. H., \& Oliveira, A. M. (2008). Adaptação à universidade em jovens calouros. Revista Semestral da Associação Brasileira de Psicologia Escolar e Educacional, 12 (1), 185202. Recuperado de http://www.scielo.br/pdf/ pee/v12n1/v12n1 a13.pdf. doi: 10.1590/S141385572008000100013

Turato, E. R. (2008). Tratado da metodologia da pesquisa clínico-qualitativa: construção teórico-epistemológica, discussão comparada e aplicação nas áreas da saúde e humanas ( $5 \mathrm{a}$ ed.). Rio de Janeiro: Vozes. 